\title{
Frank Castorf : de Kean à Hamletmaschine, ou le culte des contre-cultures
}

Frank Castorf: von Kean zu Hamletmaschine oder Gegenkultur als Kult

Frank Castorf: From Kean to Hamletmaschine, or the Cult of Counter-Cultures

\section{Sylvie Arlaud}

\section{(2) OpenEdition}

Journals

Édition électronique

URL : https://journals.openedition.org/ceg/8836

DOI : $10.4000 /$ ceg. 8836

ISSN : 2605-8359

Éditeur

Presses Universitaires de Provence

Édition imprimée

Date de publication : 1 mai 2013

Pagination : 259-274

ISBN : 0751-4239

ISSN : 0751-4239

\section{Référence électronique}

Sylvie Arlaud, «Frank Castorf : de Kean à Hamletmaschine, ou le culte des contre-cultures », Cahiers

d'Études Germaniques [En ligne], 64 | 2013, mis en ligne le 02 janvier 2020, consulté le 02 juin 2021.

URL : http://journals.openedition.org/ceg/8836 ; DOI : https://doi.org/10.4000/ceg.8836 


\title{
Frank Castorf : de Kean à Hamletmaschine, ou le culte des contre-cultures
}

\author{
Sylvie ARLAUD \\ Université Paris Sorbonne
}

Lorsque Castorf monte Kean à la Volksbühne en novembre 2008, il occupe déjà depuis seize ans le poste d'intendant de cette scène historique de l'avant-garde théâtrale allemande. On peut alors se demander si cette longévité ne doit pas nous interroger sur les limites de ce qui pourrait s'apparenter à une contre-culture institutionnalisée'. Ce rappel est nécessaire, car la pièce de Dumas est avant tout une réflexion sur la condition de l'artiste, ici le comédien Edmund Kean, asservi par la société bourgeoise. De son côté, Castorf n'a de cesse de mettre en avant la liberté créatrice accordée à son théâtre, faisant de la Volksbühne une communauté d'intérêts, un havre où le travail ne serait pas assujetti à sa valeur marchande. Mais cette fiction consciente et ironique de l'autonomie de la production théâtrale à la Volksbühne ne va pas sans heurts et s'alimente d'un combat quasi quotidien contre le public, la presse, les instances officielles et les collègues.

C'est cette réflexion sur l'art et sa subversion que Castorf a voulu placer au premier rang de sa vision du Kean de Dumas. Présenter cette mise en scène revient alors à poser la question des rapports qui existent chez Castorf entre culture institutionnelle et contre-culture ${ }^{2}$. Ne pourrait-on faire de cette dialectique le moteur principal du mode de création du metteur en scène et de sélection de l'intendant de la Volksbühne, qui répète inlassablement qu'il cherche à donner une tribune à ceux qui lui sont le plus étrangers, comme René Pollesch, Christoph Schlingensief ou Christoph Marthaler ${ }^{3}$. La contre-

\footnotetext{
1 Cité par Marvin A. CARLSON, «Frank Castorf and the Volksbühnc: Berlin's theatre of dcconstruction », in Maria M. DELGADO, Dan REBELLATO, Contemporary European Theatre Directors, New York, Routledge, 2010, p. 103-125.

2 Christopher SALTER, «Castorf's Rebellion at the Volksbühne », in American Theater, 12,1995, p. 71

3 « Wider dic Verlenzung oder 232 Jahre deutscher Lenz. Volksbühnen-Intendant Frank Castorf im Gespräch mit F. Raddatz. », in Theater der Zeit, n6, 2008, p. 17 : « Da will ich gegenhalten und solche Leute cinladen, die das völlige Gegenteil von mir sind. Die nicht im Denken aber in der Kunst das völlige Gegenteil sind. »
} 
culture investit les lieux de la culture établie ${ }^{4}$. Ou bien est-ce l'inverse ? C'est cette interdépendance que Castorf n'a eu de cesse d'interroger, et ce dès ses débuts en RDA.

La contre-culture historique, celle de la génération de 1968, sert à Castorf à transcrire la force subversive, sexuelle et politique de l'art dans la pièce romantique de Dumas. L'acteur shakespearien Kean y devient un condensé d'icône rock-pop-folk des années 1960-1970 où Hamletmaschine de Heiner Müller (1977) fait office de mode d'emploi. La réflexion de Castorf est dès lors un retour sur ses propres origines artistiques et ses opinions sur la place que doit occuper le théâtre dans la société, de l'ex-RDA et de l'actuelle Europe ${ }^{5}$. Pour faire court : Kean est une étrange évocation à la fois historique et anachronique des contre-cultures et une réflexion sur le mode de production, mais aussi sur le mode de réception et d'absorption des contrecultures par la culture dominante, à l'Ouest et à l'Est.

Pour illustrer cette thèse, il faut d'abord replacer Kean, du choix des textes et inserts jusqu'aux choix de mise en scène, dans le fil de la carrière de Castorf. En quoi le Kean de 2008 peut-il s'apparenter à un autoportrait de l'artiste en jeune homme? Dans un second point, il faudra décrypter les choix opérés par Castorf, en scrutant les différents modèles de contre-culture présents dans la pièce et leur dialogue avec la culture dominante. La culture contestataire évoquée ici va du terrorisme de la RAF à la communauté meurtrière de Ted Bundy, tueur en série américain des années 1970, en passant par la Factory de Warhol et le sexe, les drogues et le rock and roll qui ont alimenté la contestation de la dernière génération d'auteurs en RDA ${ }^{6}$. Tout l'éventail des années 1960 y est représenté. Avec Kean, c'est à la fois la capacité subversive de l'art et le drame de sa servilité (financière, idéologique, sexuelle) qui intéressent Castorf. C'est alors le danger inhérent

\footnotetext{
4 Marvin A. CARLSON, « Frank Castorf and the Volksbühne. », op. cit., p. 103.

5 Theodore ROSZAK, Vers une contre-culture, Paris, éditions Stock, 1970, p. 105-106 «Le fait que Herbert Marcuse et Norman Brown soient tenus pour les principaux théoriciens sociaux par les jeunes dissidents d'Europe occidentale et d'Amérique doit être considéré comme un des traits marquants de la contre-culture, car c'est dans leur œuvre que se produit l'inévitable confrontation de Marx et de Freud. [...] Pour Marx, ce qui est caché à la raison, c'est le caractère exploiteur du système social. La culture ('l'idéologie' au sens péjoratif du terme) s'interpose entre la raison et la réalité pour dissimuler l'action d'un inacceptable intérêt de classe... Pour Freud, ce qui est caché à la raison, c'est le contenu de l'inconscient. La culture joue son rôle dans cette tromperie, non point comme un masque dissimulant la réalité sociale mais plutôt comme un écran sur lequel le psychisme se projette lui-même à grands renforts de 'sublimation'. »"

6 Carola HÄHNEL-MESNARD mentionne ces « Hineingeborene » qui seront au centre de toute la controverse sur le Prenzlauer Berg dans La littérature autoéditée en RDA dans les années 1980. Un espace hétérotopique, Paris, L'Harmattan, 2007, p. 13. Il faudrait d'ailleurs mettre en évidence la distinction fondamentale entre la contre-culture des années 1960, engagée politiquement jusqu'à la dissidence pour certains, et la culture underground du déclin de la RDA, où l'autonomie de l'art devenait certes une forme de fronde contre l'establishment culturel et politique, mais refusait aussi toute instrumentalisation. Cf. Paul KAISER, Claudia PETZOLD, Boheme und Diktatur in der DDR. Gruppen, Konflikte, Quartiere 1970-1989, Berlin, Fannei und Walz Verlag, Deutsches Historisches Museum, 1997.
} 
au patchwork de cette multiplicité de contre-cultures, celui de leur absorption par le discours dominant, qui sera au cœur d'une dernière partie.

\section{Kean : autoportrait de l'artiste en jeune homme}

La pièce se lit d'abord comme un commentaire amusé et frondeur sur la condition de l'artiste. Kean fait le grand écart entre Baal et Falstaff. Ce choix a été le plus souvent mal perçu par les critiques, qui y ont vu les signes d'un essoufflement créatif, d'un retour sur soi et sur le petit microcosme du théâtre berlinois ${ }^{7}$. Castorf ferait du « Castorf ». Et en effet, on peut voir dans cette mise en scène un retour sur les grands mouvements de sa carrière, qui dès le début, en $\mathrm{RDA}^{8}$, pose le théâtre comme un espace possible de transformation du système de l'intérieur. C'est justement ce choix qu'il fait lorsqu'il s'attaque aux monuments culturels pour les déconstruire systématiquement et les renvoyer à leur historicité. Kean n'échappe pas à ce système, Heiner Müller non plus.

Ainsi, avec Heiner Müller, c'est une nouvelle fois l'histoire de Castorf qui s'invite, celle de sa formation d'étudiant, admirateur de la Volksbühne des années 1960 et 1970, où l'on jouait les textes de Müller ${ }^{9}$, et de sa carrière de jeune metteur en scène de textes de Müller en $\mathrm{RDA}^{10}$. Dans l'œuvre de Castorf, Heiner Müller fait à la fois figure de double et de fil rouge. En effet, Müller donne la clef de son positionnement dans sa Hamletmaschine de 1977. Il n'est ni d'un côté, ni de l'autre, mais se situe entre les deux rives ${ }^{11}$. Ces deux rives sont tant politiques qu'esthétiques, et cela vaut pour Castorf autant

7 Voir les articles de Irene BAZINGER pour la Frankfurter Allgemeine Zeitung (8.11.2008); de Anne PETER pour la Tageszeitung (10.11.2008) et de Eva BERENDT pour la Frankfurter Rundschau (8.11.2008).

8 Notons qu'il débute par une mise en scène d'Othello, qu'il replace ici comme pièce dans la pièce aux côtés de la Hamletmaschine de Müller.

9 En 1988, pour les 90 ans de Brecht, Castorf avait participé à la version radiophonique de Fatzer par Müller. Il y tenait le rôle du cuisinier. Judith WILKE, «Fatzer-Bearbeitungen », in Hans-Thies LEHMANN, Patrick PRIMAVESI, Heiner Müller Handbuch, Leben, Werk, Wirkung, Stuttgart, Metzler, 2005, p. 206.

10 «Die Vier von der Volksbühne, Sieben Jahre Volksbühne - ein Podiumsgespräch mit Hans Kresnik, Christoph Schlingensief, Christoph Marthaler und Frank Castorf, Moderation Franz Wille », in Theater heute n8-9, 1999, p. 14 : «Die Volksbühne war das Haus, das mich als Student in den sechziger und siebziger Jahren erzogen hat, es war das Theater von Heiner Müller, von Benno Besson, von Karge/Langhoff, Fritz Marquardt, ein unwahrscheinlich politischer, avantgardistischer Ort, an dem sich Menschen getroffen haben und den Mut hatten zu denken, zu reden was sie wollen - unter den bekannten Verhältnissen in der DDR. »

11 Heiner MÜLLER, "Erinnerung an einen Staat », in Krieg ohne Schlacht, Leben in zwei Diktaturen, Köln, Kiepenheuer und Witsch, 1992; p. 365: « Für meine Literatur war das Leben in der DDR etwas wie die Erfahrung Goyas in der Zange zwischen seiner Sympathie für die Ideen der Französischen Revolution und dem Terror der napoleonischen Besatzungsarmee, zwischen der Bauernguerilla für Monarchie und Klerus und dem Schrecken des Neuen, das vor seinen Augen die Züge des Alten annahm, die Taubheit seine Waffe gegen die arge Erkenntnis, weil das Auge des Malers die Blindheit verweigerte. » 
que pour Müller. Avec ces deux rives se pose d'emblée la question du renversement dialectique entre culture étatique et contre-culture subversive. Dans sa mise en scène de 1984 de la pièce de Heiner Müller, Der Auftrag, Castorf avait fait placer au fond de la scène une petite porte qui ouvrait sur le monde réel ${ }^{12}$. Une porte ouverte dans un contexte fermé, c'est toute la problématique du théâtre, de ses auteurs et de ses metteurs en scène en RDA. C'est cette politique de la porte ouverte qu'il a toujours continué de défendre. Et ce, même après la réunification, au moment de son arrivée à la Volksbühne, dont la direction valait alors pour lui acte de résistance face aux volontés d'absorption de l'Est par l'Ouest ${ }^{13}$. En guise de provocation, il fit suspendre au fronton du théâtre un gigantesque $O S T$ (EST) en lettres lumineuses rouges lorsqu'il en prit la direction.

Cette place volontairement inconfortable est aussi celle qui garantit le plus de liberté. Ni auteur pur à la Benn, ni Tendenzdichter à la Becher, Müller repousse les limites des genres et des arts, pour faire éclater la vérité derrière la façade rhétorique. C'est le but avoué de sa réinterprétation de Hamlet en 1977. À ce moment-là, les milieux de la culture en RDA sont en pleine crise, suite à l'extradition de Wolf Biermann, et la RFA est paralysée par la crise politique, intellectuelle et sociale qui traverse les milieux culturels au moment de ce qu'on a appelé l'automne allemand. De fait, la révolution esthétique est liée dans la pièce de Müller à la révolution armée, dont la charge destructrice se retrouve dans les répliques d'Ophélie, tour à tour Electre, Médée, Marie, Ulrike Meinhof, Inge Müller ou Rosa Luxemburg.

Après la mise en scène de Der Auftrag à Anklam, l'un des bastions excentrés de la contre-culture théâtrale de RDA, Castorf utilise Müller comme contrepoint dans sa mise en scène de Pension Schöller ${ }^{14}$ en y associant Die Schlacht en 1994. Rappelons que l'année même de Kean il avait déjà associé Mauser à la pièce didactique de Brecht Die Maßnahme. En 2012, la boucle semble se refermer, puisqu'il vient de monter au théâtre de l'Odéon La Dame aux camélias (de Dumas fils, 1848) en lui associant Der Auftrag et L'Histoire de l'œil de Georges Bataille. On le voit, en reprenant Müller comme grille de lecture des pièces conventionnelles ou canonisées

12 Marvin A. CARLSON, « Frank Castorf and the Volksbühne », op. cit., p. 104.

13 Theater heute, $\mathrm{n}^{\circ} 8-9,1999, \mathrm{p} .15$ : «Und ich habe immer gesagt, das ist Ost, und dieses Territorium werde ich nicht kampflos aufgeben, das ist cin Stück Zone. Aber mich hat cben bedrückt, dass wir in der DDR dic Tür nicht aufgemacht haben, den Amazonas nicht reingelassen haben, dass da kein frischer Wind war, sondern ein stinkendes, stehendes Gewässer. Ein Sumpf. » Frank Castorf revient sur sa formation dans T. IRMER, M. SCHMIDT, Die Bühnenrepublik Theater in der DDR, Ein kurzer Abriss mit längeren Interviews, Bonn, Bundeszentrale für politische Bildung, 2006, p. 247: « An der Humboldt-Universität hatte ich mich mit den historischen Entwicklungen des Theaters im Sozialismus beschäftigt, mit der Bewegung des Prolctkults, der Avantgarde, dic ja immer für sich in Anspruch nahm, letztlich an der Formung des neuen Bewusstscins teilhaben zu dürfen und zu müssen, als Kulturfront neben der Arbeits-und Wirtschaftsfront, neben den politischen Fronten. »)

14 Notons d'aillcurs que c'est cncorc la volonté historiographique de Castorf qui ressort de ec choix. La pic̀ce de Carl Lauf et Wilhelm Jacoby avait été joućc pour l'ouverture de la Volksbühne en 1915. 
auxquelles il l'associe, Castorf se penche sur les limites de sa propre contestation. Car chaque pièce, et à plus forte raison Kean/Hamletmaschine, semble mettre en scène le nivellement postmoderne de la force subversive de ces textes.

Ainsi, lorsque Kean, sous les traits d'Alexander Scheer, récite pour la première fois le fameux "Ich war Hamlet » sa diction est déformée par 1'alcool. Hagard, ses jambes ne lui répondent plus. Apeuré par le comportement, mais surtout par les paroles de son maitre, son souffleur Salomon demande : «Was war denn das? Was sprach aus Ihnen, Meister? » La réponse est à la fois un hommage et un pastiche, si l'on se rappelle que le texte de Müller tentait justement de mettre à bas toutes les autorités, et d'abord celle de l'auteur: "Es war der Tod. Mir war, als würde ich sein, wer ich bin. Heiner Müller. » La réplique de Salomon donne la clef de la lecture que propose Castorf du maître Müller : «Heiner Müller? Aber Meister, aber doch nicht so ein abgezockter teutonischer Name! $"{ }^{15}$. La lecture sera grandguignolesque.

Voilà pour Heiner Müller. Mais Dumas entre également, en tant que représentant du XIX ${ }^{\mathrm{e}}$ siècle, dans le canon de la création de Castorf. D'une part, parce qu'il traite du combat de l'artiste contre l'hétéronomie de son art. Les répliques de Kean sur la condition de l'artiste, soumis aux aléas de la critique, du public et des mécènes, sont sans ambiguïté et préfigurent les propres incertitudes de Castorf face à ce nouveau public de la Volksbühne. D'autre part, c'est la forme même du mélodrame et son contexte de production qui l'intéressent. Il choisit un texte du XIX $\mathrm{X}^{\mathrm{e}}$ siècle, à la fois expression de l'esprit bourgeois qui l'habite ${ }^{16}$ et petite porte romantique ouverte vers un ailleurs. Cette porte est celle de la liberté inhérente à tout art, défendue par Adorno ou Northrop Frye, et enfoncée tant que possible par le trublion Castorf à coups de distorsions, d'accélérations, de lacérations. Audelà de l'intrigue, c'est l'interrogation sur la forme artistique qui arrête Castorf et le renvoie évidemment vers Müller ${ }^{17}$. Chaque montage ressort de

15 « Arbeit am Verschwinden des Autors ist Widerstand gegen das Verschwinden des Menschen », in H. MÜLLER, "Der Schrecken, die erste Erscheinung des Neuen », in H. MÜLLER, Rotwelsch, Berlin, Merve Verlag, 1979, p. 1: «Solange Freiheit auf Gewalt gegründet ist, die Ausübung von Kunst auf Privilegien, werden die Kunstwerke die Tendenz haben, Gefängnisse zu sein, die Meisterwerke Komplizen der Macht. Die großen Texte des Jahrhunderts arbeiten an der Liquidation ihrer Autonomie, Produkt ihrer Unzucht mit dem Privateigentum, an der Enteignung zuletzt am Verschwinden des Autors. ”

16 Northrop FRYE, Anatomy of Criticism, Princeton, New Jersey, Princeton university press, 1957, p. 47: «We should have to say, then, that all forms of melodrama, the detective story in particular, were advanced propaganda for the police state, in so far as that represents the regularizing of mob violence, if it were possible to take them seriously. But it seems not to be possible. The protecting wall of play is still there. " La force protectrice, donc subversive, du jeu est bien ce que Castorf met en avant dans sa mise en scène, la liberté vient s'exprimer dans tous les éléments de rupture, d'interruption mis en place pendant les répétitions.

17 En somme, Castorf rejoue sur scène la querelle du formalisme dont Müller a longtemps fait les frais. Cf. Heiner MÜLLER, Krieg ohne Schlacht, op. cit., p. 290: « Durch die ästhetische Diskussion der Moderne zieht sich der Begriff Utopie. Man sagt, wenn schon nicht im Inhalt, 
cette confrontation canonique qui est indissociable de l'histoire sociale et littéraire du $\mathrm{XX}^{\mathrm{e}}$ siècle. Bourdieu avait fait de l'art au milieu du XIX $\mathrm{X}^{\mathrm{e}}$ siècle la pierre d'angle de son étude sur l'autonomie de l'art ${ }^{18}$ et la pièce de Dumas est un bon exemple de ce changement de paradigme. Elle représente, à travers les intrigues sentimentales, le déclin de l'aristocratie face à deux modes d'émancipation qui échappent à son influence : l'argent des self-made men de la bourgeoisie d'une part et l'art, ici celui du comédien, d'autre part. La pièce multiplie également les renvois à la réification de l'artiste par la société qui l'a créé et à l'aliénation de la femme par la société patriarcale. Ces deux trames sont certes plus légères chez Dumas que chez Müller, mais elles n'en sont pas moins visibles. Un résumé rapide de l'intrigue, qui sert de cadre aux évocations de Müller, Warhol et Lothar Trolle, permet de s'en convaincre.

En cinq actes et six tableaux, Dumas développe une intrigue à tiroirs autour de 1'art et des amours de l'acteur shakespearien le plus célèbre du début du XIX ${ }^{\mathrm{e}}$ siècle, Edmund Kean, archétype du génie dissolu et décadent. Kean est l'homme du peuple, artiste de foire et enfant des rues, devenu la coqueluche de la haute société londonienne et notamment de son ami, le Prince de Galles. Cette revanche sur la société féodale et hiérarchisée du Londres du début du XIX ${ }^{\mathrm{e}}$ siècle ne va pas sans crise d'identité. La nuit, Kean se déguise en marin et titube de taverne en taverne. L'acteur représente ici la condition humaine, où l'environnement dicte à l'individu son identité. Kean reste cependant subversif, c'est tout le sens de la double intrigue amoureuse. La première intrigue se tisse autour des amours contrariées entre Kean et la femme de l'ambassadeur du Danemark, le Comte de Koefeld. Kean y est le rival de son ami, le Prince de Galles, et dans cette rivalité s'expriment le désir de reconnaissance mais aussi le pouvoir de destruction de Kean. Sa séduction est sa première arme. La seconde intrigue se tisse autour du mariage forcé de la jeune héritière Anna Damby avec un aristocrate ruiné, Lord Mewill. Alors qu'elle fuit cette union qui lui répugne, elle vient chercher la protection de Kean, lui avouer son amour pour lui, mais surtout pour l'art de la comédie. En empêchant ce mariage, Kean arrache le masque des apparences et dénonce l'union forcée pour ce qu'elle est. La réflexion sur la place de l'acteur dans la société se teinte ici de critique sociale. En la protégeant, Kean soustrait la femme à sa condition d'objet d'échange. La subversion a pourtant ses limites. Le happy end ne peut avoir lieu que grâce à l'entremise du Prince de Galles :

dann liegt in der Form des Kunstwerkes ein Vorschein einer besseren Welt. Das habe ich auch immer geglaubt, mit Brecht, dass die Schönheit der Formulierung eines barbarischen Tatbestandes Hoffnung auf die Utopie enthält. Das glaube ich nicht mehr. Irgendwann muss man die Trennung von Kunst und Leben akzeptieren. Ehrenburg wurde gefragt: 'Was ist sozialistischer Realismus?' Und Ehrenburg sagte: 'Eine schwarze Orchidee.' "

18 Pierre BOURDIEU, Les Règles de l'art. Genèse et structure du champ littéraire, Paris, Seuil, 1998, p. 136-137 : «L'horreur du bourgeois se nourrit au sein même du microcosme artistique, de l'exécration de l'artiste bourgeois qui, par ses succès et sa notoriété, rançon, presque toujours, de sa servilité à l'égard du public ou des pouvoirs, rappelle la possibilité, toujours offerte à l'artiste, de faire commerce de l'art ou de se faire l'ordonnateur des plaisirs des puissants. 》 
la réputation de la Comtesse sera finalement préservée, Kean évitera la prison et pourra s'embarquer avec Anna sur le Washington en direction du Nouveau Monde et de nouveaux engagements. La crise identitaire et artistique du personnage principal devient alors le reflet de la condition de l'homme et de l'art lors du passage de la société de castes britannique à la société bourgeoise américaine.

\section{Déconstruire les contre-cultures pour les reconstruire ?}

Les deux intrigues, centrées autour de la femme-objet et de l'acteur devenu bien de consommation courante, se nouent à travers l'art et ses différentes fonctions. Une fonction curative tout d'abord. Anna trouve refuge auprès de Kean. Elle lui révèle que son art l'a sauvée et à son tour, c'est sa passion pour Kean et pour le théâtre qui va réconcilier Kean avec sa vie. La pièce se termine par une triple promesse : Kean va changer, il va s'établir à New York et se marier avec la jeune Anna Damby. En somme, Anna incarne le rêve de l'art et de l'amour pur. Avec cette réserve, toutefois, que cet art n'est autonome que parce que, en tant que riche héritière, Anna est son propre mécène, ou du moins pourra l'être dans l'exil du Nouveau Monde. La libération de l'art par le rêve démocratique américain est clairement opposée à la société de castes britannique où l'art est au service de la cour. Le voyage de Kean sur le Washington est-il alors le voyage vers l'autonomie de l'art et la modernité ${ }^{19}$ ? Cette lecture un peu naïve ne peut cependant satisfaire Castorf, pour qui cette fin heureuse ne peut être que la preuve de la récupération de l'art par le pouvoir. Chez lui, cette opposition entre l'Ancien et le Nouveau Monde, présente dans la pièce d'origine, fait «surgir» la Hamletmaschine née cette fois du voyage américain de Heiner Müller en 1976. La libération de l'art par le déplacement spatial chez Dumas est renforcée par un déplacement temporel chez Castorf/Müller : l'utopie newyorkaise de Dumas, que l'on peut lire comme une contre-culture du modèle de l'Ancien Monde, est ancrée dans une libération politique, sexuelle et sociale. Ici, cette utopie devient, surgissant du texte de Müller et de la biographie de Castorf, celle des contre-cultures des années 1960-1970 et de la Factory d'Andy Warhol, qui fit des émules tant à l'Est qu'à l'Ouest ${ }^{20}$.

19 Cette lecture est certainement aussi la clef d'une image énigmatique que Castorf propose à la fỉn de son spectacle: Anna Damby apparaît chevauchant une vache. L'image évoque à la fois le mythe d'Europe et celui de lady Godiva et semble vouloir enterrer l'Ancien Monde et ses idoles.

20 Cf. Heiner MÜLLER, Krieg ohne Schlacht, op. cit., p. 295: « Durch Andy Warhol kam ich auf Shakespeare-Factory. Das brachte mich wiederum auf die Junggesellenmaschine von Duchamp, und auf Hamletmaschine als Stücktitel. Das Suhrkamp-Projekt scheiterte daran, dass ich unbedingt das Ulrike-Meinhof-Foto nach der Strick-Abnahme darin haben wollte. [...] Ohne die Amerika-Reise hätte ich das Stück so nicht schreiben können, überhaupt nicht ohne die West-Reisen. Wichtig war das Kafka-Buch von Deleuze und Guattari, weil es von Provinz handelt, von der Mobilisierung der Provinzen. Auch die Kriminalität ist eine Provinz. » 
Castorf propose de brosser à grands traits l'histoire, ou le mythe, de l'émancipation par l'art, vision commune à nombre de programmes contreculturels, en jouant avec tous les codes théâtraux du XIX ${ }^{\mathrm{e}}$ siècle. Dans la première scène, qui est en fait le premier acte de Kean joué au pas de course, les actrices s'infligent un jeu corseté, figé. En robes de soirée, qui évoquent davantage les années 1930 que le XIX ${ }^{\mathrm{e}}$ siècle, la Comtesse et la sœur de Lord Mewill - il s'agit-là d'une réinterprétation de Castorf - sont assises sur deux chaises qui font face au public. À aucun moment elles ne se regarderont pendant leur dialogue. Derrière elles, de maigres paravents blancs, apportés au pas de course par sept comédiens, délimitent le petit espace privé dans lequel elles s'entretiennent. Le décloisonnement progressif, le désordre romantique de la pièce de Dumas, est concret chez Castorf. Le jeu est outré, le non-dit exposé, comme le réclame le nouveau souci d'explicitation et de clarté proclamé par Castorf. L'écho à son interview donnée dans Theater heute en 1998 est évident ${ }^{21}$. De fait, toutes les didascalies, qu'elles soient représentées ensuite ou non, sont dites par les acteurs et la mécanique théâtrale rendue la plus visible possible. Comme cette lettre, jetée par-dessus le paravent, à l'acte 1 . Chez Castorf, la haute société britannique incarne déjà la société de l'hypermédiatisation actuelle qu'il avait mise au centre de son procédé scénographique dans Le Maître et Marguerite. La rumeur se substitue à la réalité, le simulacre à la réalité. Toute la pièce est alors articulée autour de ces tentatives de rectification de la rumeur. La rumeur autour de l'aventure entre Kean et la Comtesse, entre Kean et l'héritière Anna Damby, contrainte à un mariage avec l'aristocrate débauché Lord Mewill. Les masques et les voiles se multiplient dans la mise en scène pour n'être que mieux arrachés.

L'art de Castorf est-il assimilable au rêve d'Anna ? Pour répondre à cette question il faut rappeler que Castorf a également fait appel à Lothar Trolle pour l'aider à réécrire la pièce 22 . Avec Trolle, c'est encore un ancien adepte de Müller, une nouvelle voix de la contestation de l'ex-RDA, qui vient

21 « Auf der Suche nach dem Trojanischen Pferd. Ein Theater-heute-Gespräch mit Frank Castorf, Volker Hesse, Ulrich Khuon und Thomas Ostermeier », in Theater heute Jahrbuch 1998, p. 31: «Die Rezeptionsweisen haben sich in den letzten zehn Jahren durch die veränderte Medienlandschaft, durch die Explosion in den Nachrichten- und Kommunikationsmitteln ebenfalls total verändert. Deshalb finde ich es wichtig, Dinge - wie es Ostermeier tut - in einem neuen Positivismus oder Naturalismus zu benennen, kenntlich zu machen. [...] Die Ästhetik des Fragmentarischen [...] wird für die nächsten Jahre nicht mehr gelten - und das tut mir leid, denn ich bewege mich lieber im Assoziativ-Fragmentarischen, weil das viel mehr Phantasie voraussetzt und weil ich mehr spielen kann. Trotzdem: wir müssen wieder alles genau benennen, wenn wir über bestimmte politische Zusammenhänge reden wollen. »

22 Sur Lothar Trolle, voir Michel CORVIN, Anthologie critique des auteurs dramatiques européens (1945-2000), Théâtrales, 2007, p. 223 et Norbert Otto EKE, « Kein neues Theater mit alten Stücken. Entgrenzung der Dramaturgien in der DDR-Dramatik seit den 70er Jahren (Müller, Braun, Brasch, Trolle) », in Hans-Christian STILLMARK, Christoph LEHKER (éd.), Rückblicke auf die Literatur der DDR, Amsterdam, Rodopi, 2002, p. 338-339. 


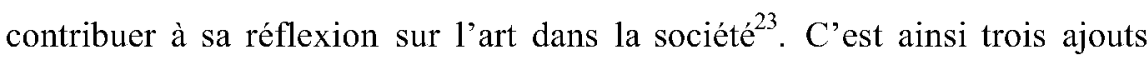
majeurs qui sont à mettre sur le compte de cette réécriture, qui tous répondent à l'écriture dramatique diégétique, privilégiée par Trolle. La narration vient se substituer à la mimésis et s'oppose de fait aux techniques «performatives" mises en place par Castorf. Il s'agit d'abord de deux passages à sources documentaires tirées de l'histoire sociale de l'Empire britannique du XIX siècle et qui démontrent tous deux la valeur de contre-pouvoir que pouvaient alors avoir les médias anglophones. Le premier passage relate l'exploitation inhumaine des enfants dans les usines de tissage et traduit des passages de la biographie du tisserand Robert Blincoe, publiée sous forme de feuilleton dans le journal The Lion en $1828^{24}$. Le second passage revient sur le massacre dit de "Peterloo ", la répression policière particulièrement violente d'une manifestation prolétaire le 16 août 1819 à Peter's Field à Manchester, délocalisé pour les besoins de la pièce sur Drury Lane $e^{25}$, lieu symbolique qui relie le théâtre de Kean à la contestation sociale. Ces deux textes sur l'aliénation de l'individu par le travail, publiés d'abord dans des journaux, sont dits par les deux figures du pouvoir, Lady Mewill et le Prince de Galles. Ils surgissent comme des commentaires historisants qui placent la société aristocratique, qui seule s'exprime ici, dans le contexte de ses conditions d'existence, comme n'a de cesse de le souligner le Prince de Galles en parlant de «ses » policiers. Ces inserts à caractère documentaire, mais narratifs, sont reliés thématiquement à la mort du fils de Kean, petit sacrifié de la carrière de son père, père qui, alors que son fils est à l'agonie, va jouer Shylock sur les planches londoniennes. La célébrité a donc son prix : une livre de chair humaine.

Notons que cet ajout, destiné à faire parler les exclus de la pièce, fait aussi le lien entre Castorf et la tradition naturaliste allemande. Car le texte de Trolle renvoie à deux manifestes naturalistes : à la pièce à scandale de Gerhart Hauptmann, Die Weber, et à la nouvelle Papa Hamlet, de Arno Holz et Johannes Schlaf, dont les interférences thématiques avec le destin de Kean sont nombreuses. La nouvelle racontait la déchéance d'un couple d'acteurs, dont l'enfant mourait étouffé par la négligence de sa mère et la violence égocentrique de son père. La pneumonie évoquée chez Castorf fait écho aux accès de toux du petit enfant dans Papa Hamlet. La mort de l'enfant, dans la littérature naturaliste, est le signe du conflit générationnel et de la responsabilité partagée par les conditions socio-économiques et le caractère égocentrique du personnage central. Et c'est justement ce rôle de

23 Sur la politique de programmation en RDA dans les petites villes nous renvoyons à Laure DE VERDALLE, Le théatre en transition : de la RDA aux nouveaux Länder, Paris, éditions de la Maison des Sciences de l'Homme, 2006, p. 155.

24 John BROWN, A Memoir of Robert Blincoe, an orphan boy, sent to endure horrors of a cotton-mill, Manchester, J. Doherty, 1832.

25 La misère dans les rues de Drury Lane fera également l'objet d'articles publiés par Charles DICKENS dans le recueil Sketches of Boz. Les souvenirs de Blincoe semblent également avoir inspiré à Dickens certains passages d'Oliver Twist. Il est probable que la délocalisation du massacre sur Drury Lane relève de ce croisement intertextuel. 
contextualisation sociale et historique que Castorf fait jouer aux inserts émotionnels de Trolle. Chez Castorf, la mort de l'enfant de Kean ${ }^{26}$, seul moment d'émotion au premier degré, fait intervenir un autre personnage sur scène, qui n'existait pas non plus chez Dumas ou chez Sartre. Il s'agit de la femme de Kean, Mary, qui fait le pont entre le monde ultra-réaliste des victimes de la société industrielle et le monde délibérément factice de la Factory de Warhol et de son Velvet Underground ${ }^{27}$. La biographie de Mary est celle de Nico, chanteuse du Velvet ${ }^{28}$. Á cet égard, les renvois à Andy Warhol sont toujours, jusque dans leur ironie, des renvois à Castorf, à son passé d'auteur de l'Est, à son mode de création communautaire et à l'effacement délibéré des codes régissant culture élitiste et culture de masse.

Deux contre-cultures viennent donc s'imbriquer dans les deux textes originaux. Une contre-culture sociale et politique (ancrée dans le monde réel), évoquée ici par le récit de l'aliénation du prolétariat, surgie logiquement du contexte de Dumas. Et une contre-culture artistique, celle de la Factory de Warhol et de toute la culture folk, rock, pop des années 1960 et 1970, à laquelle on peut associer assez librement, comme le fait Castorf, les icônes de la contestation armée que sont Meinhof, Baader et Ensslin. La Factory surgit naturellement du texte de Müller, écrit en Bulgarie après son séjour américain de 1975-76, et dont les thèses de Warhol avaient servi à construire le titre ${ }^{29}$. Cette seconde contre-culture du pop art, incarnation ludique du nivellement postmoderne entre culture et sous-culture où le capitalisme devient une forme artistique, s'invite sur scène progressivement et fait du rêve américain d'Anna Damby le rêve warholien de Castorf. À la culture, il répond, tout comme Warhol, par la force révélatrice de 1'acteur «culte», dont Kean pourrait être la matrice ${ }^{30}$. Dans son entretien de 1998 avec la revue Theater heute, il avait dessiné son projet esthétique de la façon suivante : «Deuxièmement : je veux devenir une machine, comme le réclamait Andy Warhol. Je veux atteindre le

26 Comme l'a fait justement remarquer Emmanucl Bćhague dans la discussion, lors du colloque de février 2012, l'émotion est souvent remisée sur grand ou petit écran dans les mises en seène de Castorf. Dans un monde de simulacres, l'authenticité trouve refuge derrière l'ćcran. Il indiquait à cet égard la mise en scène des Mains sales en 1995 et celle des Tisserands en 1997, qui toutes deux entrent en résonance de façon intertextuclle avec lc présent spectacle.

27 Johann KUGELBERG, The Velvet Underground, un mythe new-yorkais, Now York, Rizzoli, 2009.

28 De ses amours avec Alain Delon jusqu'à une overdose, tous les fragments médiatisés de son histoirc s'y retrouvent. En cc sens, Trolle a travaillé à partir d'cxtraits de pressc, que ce soit pour Petcrloo ou pour Nico. On y perçoit une histoire de la presse qui mène de ses débuts émancipateurs à son retournement dialcetique : aliénation par le viol de l'intimité. Là encore, la presse sert de miroir à l'histoire du renversement dialectique des contre-cultures.

29 «Über Hamletmaschine », in LEHMANN, PRIMAVESI, Heiner Müller Handbuch, p. 221-225. Cf. aussi supra, notc 20 .

30 Klaus HONNEF, Andy Warhol, 1928-1987, De l'art comme commerce, Colognc, Taschen, 2000. p. 8 : «Andy Warhol incarnait à la perfection le nouveau type de star. $\dot{A}$ la fois créatcur, réalisateur et actcur, il a apporté au monde l'artiste-star qui, dans l'univers artistique, succéda au génic. [...] Pcrsonnc n'a interprété le mécanisme du culte des stars micux que l'artiste Andy Warhol. Tout à la fois présent et absent il faisait penser à unc apparition incarnćc. ) 
summum de l'émotion, du voyeurisme, du sexuel, pour moi, pour les acteurs, pour les spectateurs. L'intelligence relève d'un mode de discernement qui vient de l'intuition. »" Warhol lui sert alors de programme esthétique paradoxal mais aussi de grille de lecture à la nouvelle fonction de l'artiste dans la société de consommation ${ }^{32}$.

Chez Dumas, Kean était l'incarnation du génie romantique et asocial, chez Castorf, par l'intermédiaire de Müller et de Warhol, il est celle de l'artisteculte. De fait, sur scène, Kean a tout d'une rock star. Ses accoutrements et ses postures font penser tour à tour à Mick Jagger, Keith Richards, Lou Reed ou Jésus-Christ superstar, les chansons, arrangées et écrites par Steve Binetti, retracent l'histoire de la musique contestataire, entre Metallica et le Dirty old town des Pogues ${ }^{33}$. Ce même souci archéologique, qui revient à poser l'historicité de cette forme de contestation, prédomine également dans les inserts dansés, qui vont, dans l'ordre du chaos, du slow au pogo. La structure même de la pièce, où le délitement progressif de la belle architecture du texte de Dumas par le chaos formel des pans de texte de Müller accompagne le délitement de la société bourgeoise par la force subversive de l'art, fait des interludes musicaux les révélateurs d'un changement dans le rapport de force. Peu à peu, les voix masculines, dont celle d'Alexander Scheer lui-même, laissent la place aux voix féminines ${ }^{34}$. Mary, sa femme, venue lui rappeler l'anniversaire de la mort de son fils, évoque la possibilité d'un ailleurs: « New York, aller chez Lou, aller chez Andy ». Une conversation téléphonique «d'Alex » avec Uschi Obermeier se termine ainsi : «Est-ce que je peux emmener Frank Castorf ? ${ }^{35}$ Tout comme Müller mettait en garde en 1989 contre la position confortable de l'artiste, privilégié ${ }^{36}$, Castorf se moque ici de lui-même et du monde du théâtre en lui opposant le prolétariat du XIX siècle.

31 Theater heute Jahrbuch 1998, p. 38.

32 On pourrait prétendre que Castorf, à travers Warhol, suit le précepte d'Adorno dans "Kulturindustric. Aufklärung als Masscnbetrug », in Max HORKHEIMER, Theodor W. ADORNO, Dialektik der Aufklärung, Francfort/Main, Fischer, 1994, p. 166 : « Dic reinen Kunstwerke, die den Warencharakter der Gesellschaft allein dadurch sehon verneinen, dass sie ihrem eigenen Gesetz folgen, waren immer zugleich auch Waren. »

33 Les chansons composées par Steve Binetti résument les bouts d'intrigue à la manière des songs de Brecht.

34 Les Ophélics, venues avec Anna Damby réclamer leur place de lumière sous les projecteurs, évincent Kean devant le miero.

35 Castorf jouc avec la célébrité de son acteur vedette: Alexander Scheer venait d'incarner Keith Richards dans un film sur Uschi Obcrmcier.

36 Heiner MÜLLER, «Plädoyer für den Widerspruch, in Neues Deutschland, 1989 », in Krieg ohne Schlacht, op. cit, p. 426 : « Ich bin kcin Wortführer cincr Bewcgung. Entscheidend ist, dass endlich dic Sprachlosen sprechen und dic Steine reden. Der Widerstand von Intellektuellen und Künstlern, dic seit Jahrzehnten privilegiert sind, gegen den drohenden Ausverkauf wird wenig ausrichten, wenn ein Dialog mit der lange schweigenden oder Fremdsprachen redenden Mehrheit der jahrzehntelang Unterprivilegierten nicht zustande kommt. 》 
Évidemment, une mise en scène de Castorf permet toujours une lecture à plusieurs niveaux. Il développe une lecture immédiate, intuitive dirait-il, où le comique de situation, de répétition, les courses effrénées des acteurs d'un bout à l'autre de la scène, la sidération visuelle de certaines images, comme la crucifixion de Kean, le slow homo-érotique entre Kean et le Prince de Galles, l'entrée d'Anna à dos de vache ou encore celle des femmes-louves du Club des Loups, sans parler du Scherzo de Hamletmaschine devenu une coursepoursuite à la Benny Hill, interpelle tous les publics. Cet art jubilatoire, fondé sur le corps des acteurs, fonctionne en contrepoint d'une autre lecture presque historique, où la connaissance des textes, mais aussi de l'histoire des mises en scène, fait ressortir la très grande assise culturelle de Castorf dans son travail de mise en scène. N'oublions pas qu'il se destinait d'abord à une carrière universitaire $^{37}$ et que ce fondement intellectuel et culturel fait certainement la profondeur de son théâtre, mais peut-être aussi sa propre contradiction, puisque les pièces ne sont alors perceptibles dans leur globalité que par la communauté des happy few ${ }^{38}$. Le nivellement postmoderne entre culture et sous-culture et le renversement dialectique de l'hétéronomie de l'art, dont Warhol a fait le programme de son art délibérément commercial, sont magistralement incarnés par une scène rajoutée. Après l'acte d'exposition de Kean, Castorf propose un interlude, dans lequel la troupe des acteurs s'assoit à l'avant-scène pour réciter, avec la même conviction, qui un slogan publicitaire, qui un poème de Goethe faussement attribué à Kleist, Brecht ou Schiller. Après avoir rejoué une course d'obstacles et remis les prix aux gagnants, les acteurs lancent des cacahuètes à une version en carton-pâte de Kean. Ce petit condensé de mise en scène à la Castorf relie clairement le nivellement culturel, et l'inculture qui en résulte, à la société de consommation. L'art n'est plus que slogan et l'artiste qu'un singe savant. Le Heil Coca cola de Heiner Müller résonnera plus tard, mais en fin de compte, il est déjà audible ici et pose une relation causale toute brechtienne entre capitalisme et fascisme.

\section{La contre-culture absorbée par la culture ?}

Les contre-cultures, si elles sont bien au centre de la pièce, n'en sont pas moins problématiques. Tout d'abord, Castorf met en scène leur historicité. Pour le XIX ${ }^{\mathrm{e}}$ siècle, ce sera la contre-culture des bas-fonds : celle de la boxe,

37 Castorf a soutenu un mémoire de recherche à l'Université Humboldt en 1976 sur «Grundlinien der Entwicklung der weltanschaulich-philologischen und künstlerischästhetischen Positionen Ionescos zur Wirklichkeit. » Cf. Marvin A. CARLSON, «Frank Castorf and the Volksbühne... », op. cit., p. 104.

38 Pour étayer cette remarque, je rappellerai que la mise en scène des premières répliques d'Ophélie, jouée par Anna, cachée par un voile noir, renvoie non seulement au texte de Dumas, mais aussi à l'histoire de la mise en scène de Hamlet au $\mathrm{XIX}^{\mathrm{e}}$ siècle. Cette historicité touche tant à l'histoire du théâtre qu'à l'histoire de la musique : après la guitare acoustique vient la guitare électrique, la musique passe du folk au rock, puis au hard rock. 
du Club des loups et des cabrioles des saltimbanques. Pour le $\mathrm{XX}^{\mathrm{e}}$ siècle, c'est l'univers rock-pop de Warhol et de la mercantilisation comme art et arme contre la bourgeoisie ${ }^{39}$. Pour faire court : avec Warhol, Castorf pose la dialectique de la contre-culture devenue culture et donc de la limite de toute contre-culture. Car, en effet, si les contre-cultures sont produites par la société qu'elles contestent, elles en sont, plus que des remises en cause, des soupapes nécessaires à la survie de ce qu'elles combattent en apparence. Et cela vaut autant pour la boxe que pour le rock ou le théâtre.

Cette interprétation du renversement dialectique de la force libératrice de l'art n'est pas sans rappeler la critique que formulait Brecht à l'encontre de la machine théâtrale dès Mahagonny. La réponse de Brecht passe par une remise en question fondamentale du mode de production et de réalisation du théatre, dont le théâtre épique est l'une des possibilités. Mais la machine théâtrale est puissante, et même le théâtre épique a fini par s'émousser. Le choc culturel qu'il pouvait induire en 1930, ou même encore dans l'Europe de l'aprèsguerre, a fini par devenir une ritournelle. C'est maintenant au tour du théâtre dit postdramatique d'essuyer les mêmes critiques. Lorsque Heiner Müller cherche un theâtre qui puisse formuler la réalité postmoderne, il écrit Hamletmaschine et signe un manifeste de ce que Hans-Thies Lehmann désignera plus tard par le terme maintenant presque galvaudé de théâtre postdramatique. Le texte, très dense, est un montage-collage de sources littéraires, populaires, médiatiques, philosophiques et biographiques permettant une lecture actuelle du drame de Shakespeare et de l'époque contemporaine, marquée par le terrorisme en Allemagne et l'extradition de Biermann par la RDA. En cinq mouvements, qui alternent les fragments monologiques d'un Hamlet et d'une Ophélie, ou d'un chœur d'Ophélies, devenues des Electres, Müller retrace l'histoire de la destruction de la culture occidentale après 1945. Le décor s'ouvre sur les ruines de l'Europe et termine par un monde sous-marin, ophélien, peuplé de lambeaux de corps et de chair. Entre ces deux extrêmes la destruction fait rage, destruction de la forme, destruction de la culture, fin des idéologies, destruction des générations, des frontières entre les sexes... tout dans le texte n'est que transgression et renversement pour retrouver une sorte de chaos originel qui ne peut s'apparenter à l'innocence de l'art. Inutile de dire que ce texte a été perçu comme un condensé formaliste dissident et que sa création ne put d'abord avoir lieu qu'en France et en Belgique. Voir Hamlet trancher la tête de Marx, Lénine et Mao ne semblait pas possible en RDA. Hamletmaschine est en ce sens un condensé de contre-culture, tant dans son attaque systématique contre les catégories dramatiques que dans les textes et idées qui y sont convoqués.

Chez Castorf, Hamletmaschine vient s'imbriquer dans l'architecture rigoureuse de Dumas, pour peu à peu la faire imploser. Il garde entièrement le premier et le dernier acte de Dumas, mais remplace presque toutes les scènes centrées sur l'art de la comédie, la pièce dans la pièce, par des extraits de

39 Andy WARHOL, Ma philosophie de $A$ à $B$ et vice-versa, Paris, Flammarion, 1977. 
Müller. Ainsi, Kean récite Hamletmaschine au lendemain d'une beuverie, Anna Damby, et ses avatars masqués, prouvent leur amour du théâtre à Kean, non pas en récitant les vers de l'Ophélie de Shakespeare, mais ceux de Müller. Dumas sert ici clairement de cadre, de carcan à un univers chaotique et subversif, et signale que cette contre-culture n'existe que dans le cadre de cette autre culture dont elle dépend. Le public de Kean est avant tout celui de la haute société. Avec l'arrivée de Mary-Nico, l'envoyée du Velvet Underground, la destruction du cadre va s'accélérer. L'intrigue de Dumas est presque oubliée et il n'en reste plus que la réflexion sur les liens entre l'art et la société.

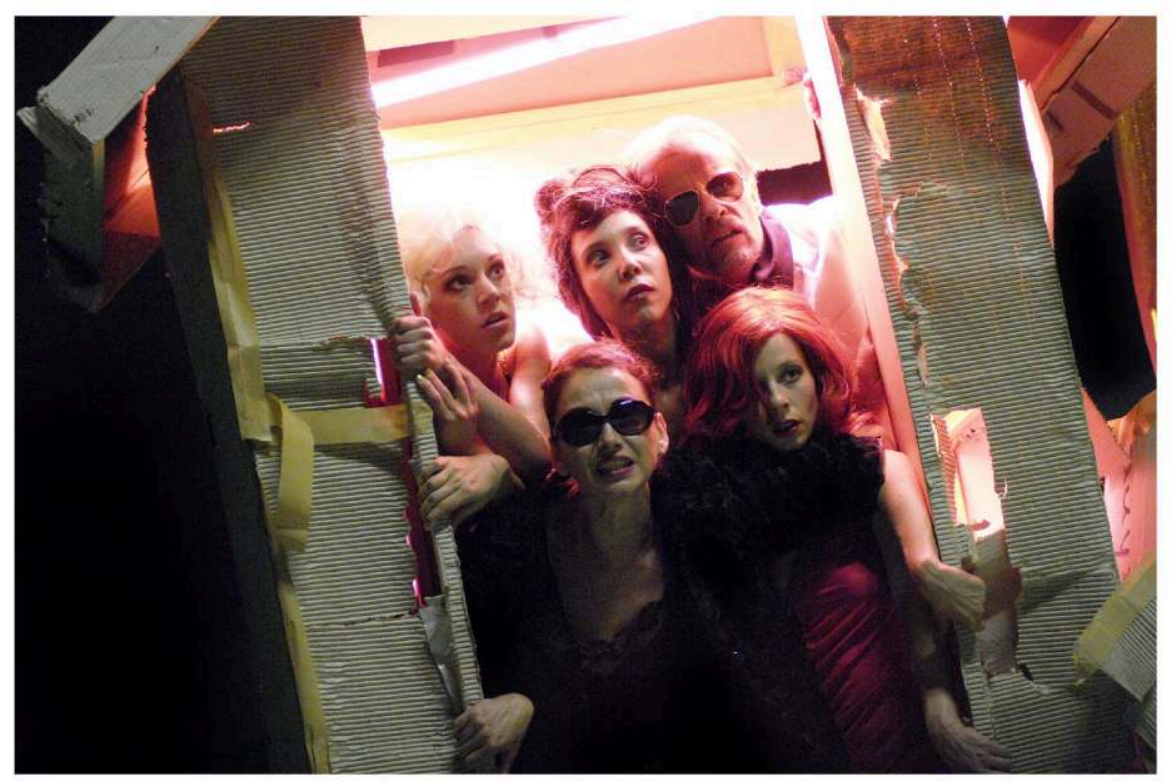

La culture joue à la contre-culture : Hamlet et Ophélie (Hamletmaschine),

interprétés par le comte et la comtesse de Koefeld en lunettes noires (Kean), entourés des « louves » qui incarnent Mao, Marx et Lénine.

Kean de Frank Castorf (2008). (C) Thomas Aurin.

Le Scherzo de Hamletmaschine devient ainsi le morceau de résistance de la pièce de Dumas : au lieu d'être cantonnés à la troupe des acteurs de Kean, les rôles de Hamlet et Ophélie sont maintenant joués, entre autres, par les acteurs qui incarnent le Comte et la Comtesse Koefeld. Ils s'emparent du texte et la Comtesse, habillée en simili-terroriste, pointe un fusil mitrailleur vers les autres acteurs, soit les trois femmes censées incarner les icônes idéologiques, Mao, Lénine et Marx. Sous la contrainte, elle les force à dire le texte par lequel Marx exhortait les hommes à se libérer de leur aliénation : "Es gilt alle Verhältnisse umzuwerfen, in denen der Mensch...». L'émancipation révolutionnaire devient alors une contrainte. Que révèle cette 
mise en scène ? Elle pose d'abord la charge totalitaire de tout programme idéologique, de même que son danger dialectique, c'est-à-dire la reprise en main de la contre-culture par les représentants de la culture dominante. Dans le cas présent il s'agit des aristocrates qui jouent à la révolution. Mais Castorf pense aussi, comme Müller, aux cadres de la RDA et à leurs préceptes marxistes ${ }^{40}$. Notons que le Prenzlauer Berg et ses liens souterrains avec la Stasi sont un bel exemple ${ }^{41}$ de contre-culture absorbée par la culture officielle.

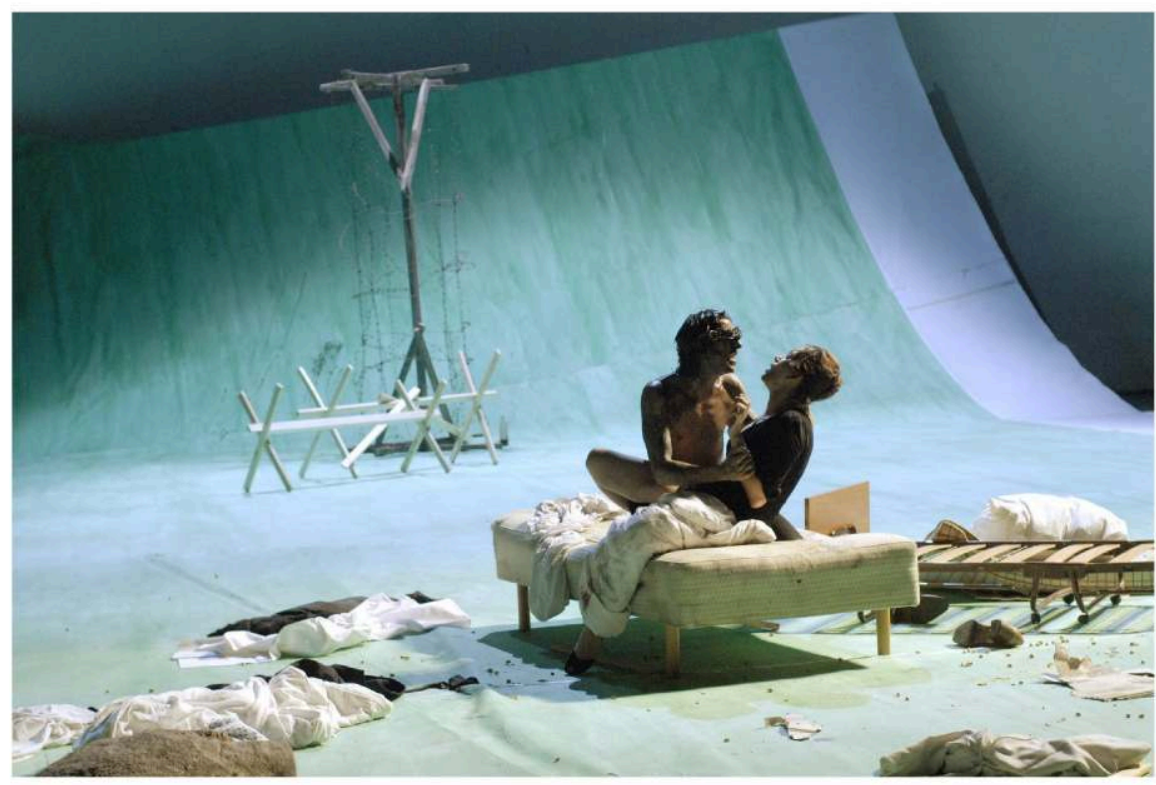

Kean, la croix et le Prince de Galles, une illustration de l'autonomie de l'art au $\mathrm{XIX}^{\mathrm{e}}$ siècle. Kean de Frank Castorf (2008). (C) Thomas Aurin.

Le vrai pouvoir est alors celui du pouvoir d'expression, que ce soit à Londres ou à Berlin-Est. Rappelons que ce sont les "capitalistes », Lady Mewill et le Prince de Galles, qui racontent l'horreur de l'exploitation des tisserands et de la répression brutale d'une manifestation pacifique. Mais l'aliénation ne se limite pas au prolétariat. L'acteur, l'individu au second degré qui ne vit que par ses rôles et qui ne distingue plus entre réalité et

40 Chez Müller, les icônes de Marx, Lénine et Mao étaient tranchées par Hamlet à grands coups de hache, signalant la fin des idéologies. Ici, c'est Ophélie-Hamlet qui tient en joue trois femmes, dont on nous dit qu'elles sont nues alors qu'elles ne le sont pas. La didascalie parlée dit en outre que ces trois femmes sont Marx, Lénine et Mao, ce qu'elles " confirment » en récitant le texte de Marx, en allemand, en russe puis en pseudo-chinois. Le nivellement entre culture et contre-culture est alors aussi et surtout un nivellement qui sert en fait à la culture dominante à asseoir son emprise.

41 Alison LEWIS, Die Kunst des Verrats, Der Prenzlauer Berg und die Staatssicherheit, Würzburg, Königshausen et Neumann, 2003. 
fiction, est l'être aliéné par excellence. La pièce pose l'aliénation de l'homme par la société bourgeoise, mais surtout le mythe de la libération de l'aliénation par l'art. Ce mythe est au cœur de la transformation christique de Kean, oscillant entre martyre et mythomanie. Le sacrifice renvoie ici à la question de l'authenticité de l'art et joue avec l'art subversif des années 1960 et 1970, où Hermann Nitsch (1964, Fünfte Aktion) ou Marina Abramovic (1975, Die Lippen des Heiligen Thomas) mettaient, à travers la figure du sacrifice, de soi ou de l'autre, le spectateur devant ses propres responsabilités ${ }^{42}$. On peut voir une réminiscence de cet art, né de la génération de 1968, dans les scènes, où Anna Damby s'allonge sur des barbelés pour s'offrir à Kean et à l'art ; et où Kean accepte son rôle christique. L'esthétique de la souillure, chère à Castorf, accentue ici le sacerdoce de l'acteur. Le visage creusé, le corps barbouillé de noir pour jouer Othello, il sera ensuite hissé sur une Croix par le Prince et le Comte, aspergé de sang, affublé d'une couronne d'épines, alors que Mme Koefeld, telle Marie-Madeleine, se prosterne à genoux devant la croix. Ces transformations concrétisent le prix de la célébrité, le sacrifice imposé par la société qui se repaît de sa célébrité et de son " génie ».

Mais l'ironie de la pièce veut que la passion christique ne reste qu'un subterfuge. Kean ne sauve personne; le véritable deus ex machina n'est autre que le Prince de Galles. C'est grâce à lui que la femme adultère sera sauvée, la peine de prison de Kean commuée en bannissement et la fuite d'Anna Damby rendue possible. La grande convention de cette fin, où, comme dans Minna von Barnhelm, le puissant résout tous les conflits du drame, fait le sel de cette pièce. Kean, le subversif, termine en petit-bourgeois dans sa banlieue américaine. Si l'on en croit Brecht, il s'agit-là plus d'un enfer d'inculture que d'un paradis de contre-culture. Le Prince a gagné.

Ce qui ressort de la mise en scène de Castorf est l'ironie constante avec laquelle il déshabille tant Kean que la Hamletmaschine ou le pop art de Warhol. Une ironie qui fait ressortir la contre-culture dans son historicité, à l'Ouest et à l'Est, et par conséquent met en exergue son inefficacité. Est-ce pour autant un constat d'impuissance ? À l'évidence, Castorf hésite entre plusieurs voies esthétiques anti-mimétiques : il s'engouffre avec délectation dans la destruction des idoles en usant de recettes postdramatiques commentées par un cri du coeur de Kean : «Bloß jetzt kein modernes Theater $» !$ Mais il tente aussi une incursion du côté de la sobriété narrative grâce aux inserts diégétiques de Trolle. Grâce à lui, ce sont les oubliés de l'histoire qu'il veut replacer au centre de l'appareil médiatique. Mais ce sont justement ces inserts qui ont le moins convaincu la presse. Le Prince a-t-il encore gagné ?

42 Erika FISCHER-LICHTE, Theater seit den 60er Jahren, München, UTB, 2010, p. 30 et p. 34 